\title{
Retaliation in Response to Castration Promotes a Low Level of Virulence in an Ant-Plant Mutualism
}

\author{
Pierre-Jean G. Malé · Jean-Baptiste Ferdy $\cdot$ Céline Leroy $\cdot$ Olivier Roux \\ Jérémie Lauth · Arthur Avilez · Alain Dejean · Angélique Quilichini · \\ Jérôme Orivel
}

\begin{abstract}
The diversion of a host's energy by a symbiont for its own benefit is a major source of instability in horizontally-transmitted mutualisms. This instability can be counter-balanced by the host's retaliation against exploiters. Such responses are crucial to the maintenance of the relationship. We focus on this issue in an obligate ant-plant mutualism in which the ants are known to partially castrate their host plant. We studied plant responses to various levels of castration in terms of (1) global vegetative investment and (2) investment in myrmecophytic traits. Castration led to a higher plant growth rate, signalling a novel case of gigantism induced by parasitic castration. On the other hand, completely castrated plants produced smaller nesting and food resources (i.e. leaf pouches and
\end{abstract}

\footnotetext{
P.-J. G. Malé · J.-B. Ferdy · A. Avilez

ENFA, UMR5174 EDB (Laboratoire Évolution \& Diversité

Biologique), Université de Toulouse, 118 route de Narbonne,

31062 Toulouse, France
}

P.-J. G. Malé · J.-B. Ferdy · A. Avilez

UMR5174 EDB, CNRS, Université Paul Sabatier,

31062 Toulouse, France

\section{P.-J. G. Malé $(\bowtie)$}

Laboratoire Evolution \& Diversité Biologique, Université Paul Sabatier, 118 route de Narbonne,

31062 Toulouse Cedex 9, France

e-mail:pjg.male@gmail.com

C. Leroy

UMR 123, AMAP (botAnique et bioinforMatique de

l'Architecture des Plantes), IRD, Boulevard de la Lironde,

TA A51/PS2, 34398 Montpellier Cedex 5, France extra floral nectaries). Since the number of worker larvae is correlated to the volume of the leaf pouches, such a decrease in the investment in myrmecophytic traits demonstrates for the first time the existence of inducible retaliation mechanisms against too virulent castrating ants. Over time, this mechanism promotes an intermediate level of castration and enhances the stability of the mutualistic relationship by providing the ants with more living space while allowing the plant to reproduce.

Keywords Evolutionary conflict - Cheater . Overexploitation $\cdot$ Mutualism breakdown $\cdot$ Allomerus decemarticulatus $\cdot$ Hirtella physophora

\section{Introduction}

Mutualisms are defined as reciprocally beneficial interactions between organisms, but they can also be viewed as

\section{O. Roux}

UMR 224, Maladies Infectieuses et Vecteurs Ecologie,

Génétique, Evolution et Contrôle, IRD, BP 171,

Bobo Dioulasso 01, Burkina Faso

J. Lauth · A. Dejean · A. Quilichini · J. Orivel

UMR 8172, Ecologie des Forêts de Guyane, CNRS, Campus

Agronomique, BP 316, 97379 Kourou Cedex, France

A. Dejean

UMR Ecolab, Université de Toulouse, 118 route de Narbonne, 31062 Toulouse Cedex 9, France 
'reciprocal exploitation', thus involving both benefits and costs (Herre et al. 1999). Since natural selection favours individuals that are able to lower their costs and/or increase their benefits, conflicts in resource allocation are expected to cause mutualistic relationships to shift to parasitism (Bronstein 2001; Edwards et al. 2010). Striking examples are well-known in the framework of pollination mutualisms. Cheating has evolved in both partners and while some plants produce flowers devoid of nectar, some insects can rob nectar without pollinating their partner (Gilbert et al. 1991; Inouye 1983).

The reproduction of each partner engaged in any horizontally-transmitted mutualism is obviously subjected to a conflict since the resources invested by one partner in its own reproduction are lost for the other partner. Such a trade-off is a major source of instability as, over time, the symbionts may evolve in such a way that they end up completely sterilizing their hosts. Incomplete sterilization is thus considered 'suboptimal virulence' in the literature (Jaenike 1996; O'Keefe and Antonovics 2002), which highlights the existence of counterbalancing mechanisms such as the local dispersal of both partners, partner choice and/or retaliation against exploiters (Wilkinson and Sherratt 2001; Szilágyi et al. 2009).

Ant-plant mutualisms provide an interesting framework for studying such reproductive trade-offs. Myrmecophytic plants typically provide ants with a nesting space in hollow structures such as thorns or leaf pouches, and sometimes food resources, in exchange for protection against predators and competitors. These relationships are horizontally transmitted and because of this mode of transmission, ants should evolve to be parasitic on their hosts (Heil and McKey 2003; Wilkinson and Sherratt 2001). Moreover, because of the obligatory nature of most of these relationships, the plants cannot escape such exploitation by ending the interaction without drastically reducing their fitness. It has been demonstrated in several model systems that the growth of the ant colony is constrained by the nesting space provided by the plant (Fonseca 1993; Orivel et al. 2011). The ants can take advantage of the trade-off between the plant's reproduction and growth and induce gigantism in their host plant by castrating it (Frederickson 2009). Such a conflict between the reproduction of the plant and the growth of the ant colonies is illustrated by the castration behaviour exhibited by several plant-ants (Yu and Pierce 1998; Izzo and Vasconcelos 2002; Gaume et al. 2005; Malé et al. 2012). This is, however, based on the major assumption that there is a trade-off between vegetative growth and reproduction in myrmecophytes. Yet, given the modular growth and autotrophy of plants, each module could theoretically be able to pay its own resource costs, for example, through greater photosynthesis in nearby leaves and in some of its floral structures (Watson 1984; Obeso 2002).
Despite the ant-induced limitations to their reproduction, myrmecophytes manage to reproduce even in the presence of ants. An intermediate level of castration has indeed been observed in associations involving Allomerus plant-ants that probably results from tolerance and/or local dispersal mechanisms (Edwards and Yu 2008; Izzo and Vasconcelos 2002; Malé et al. 2012; Szilágyi et al. 2009). However, although never studied in these systems, resistance mechanisms are thought to result in the same pattern of intermediate virulence. Indeed, retaliation mechanisms have recently been identified as a key factor in preventing cheating in ant-plant mutualisms, especially in the case of cheating by defection (Edwards et al. 2006, 2010). But castration behaviour belongs to another kind of cheating mechanism; namely, overexploitation. In the case of defection, cheating results in a reduction in the partner's benefits, while overexploitation leads to an increase in its costs (Douglas 2008, 2010). Moreover, tolerance and resistance mechanisms lead to very different evolutionary paths (Best et al. 2009). As a consequence, proving the presence/absence of resistance mechanisms in ant-plants is critical to our understanding of the maintenance of such relationships despite possible exploitation.

In this study, we focus on one of these plant-Allomerus systems involving Hirtella physophora and A. decemarticulatus in which an intermediate level of castration virulence has been demonstrated (Malé et al. 2012). We aimed to quantify (1) the net benefit of castration for the resident ants in terms of the plant's vegetative growth and thus available nesting space, (2) the plant's response to castration in terms of its investment in myrmecophytic traits (i.e. leaf pouches and extra-floral nectaries), and (3) the putative consequences of any change in the myrmecophytic traits for the ant colony. We experimentally addressed this issue by assessing the plant's investment in myrmecophytic traits when castration is partial, complete or non-existent and analysed the implications of the different plant responses (i.e. gigantism and retaliation) on the continuance of the mutualistic relationship.

\section{Materials and Methods}

\section{Study Sites and Model}

This study was conducted in French Guiana between August 2008 and December 2011 on two populations of $H$. physophora less than one kilometre apart in the area of Petit Saut, Sinnamary $\left(05^{\circ} 03^{\prime} 30^{\prime \prime} \mathrm{N} ; 52^{\circ} 58^{\prime} 34^{\prime \prime} \mathrm{W}\right)$ and one population at the Nouragues research station $\left(04^{\circ} 04^{\prime} 18^{\prime \prime} \mathrm{N}\right.$; $\left.52^{\circ} 43^{\prime} 57^{\prime \prime} \mathrm{W}\right)$.

Hirtella physophora is an understory treelet that occurs strictly in pristine Amazonian rainforest. Plant individuals 
have long-lived leaves that bear a pair of pouches (i.e. domatia), at the base of each lamina (Leroy et al. 2008). The domatium results from the curling under of the leaf margin and the tissues show profound morpho-anatomical modifications compared to the leaf lamina (Leroy et al. 2010). Circular extra-floral nectaries (EFNs) occur on the abaxial surface of the lamina and inside the domatia. They differ morphologically, with the EFNs in the domatia being three times larger than the ones on the lamina (Leroy et al. 2008). H. physophora is a self-incompatible, entomogamous species and two flowering periods can be distinguished annually: from December to February and June to August (Malé 2011).

In the study area, plant individuals are almost exclusively inhabited by $A$. decemarticulatus with a single colony per plant (Solano et al. 2003). Moreover, A. decemarticulatus has never been found in association with another myrmecophyte (Grangier et al. 2009). As in any other protective mutualism between ants and plants, A. decemarticulatus workers protect their host plant from defoliators, thus favouring its vegetative growth (Grangier et al. 2008; Orivel et al. 2011). However, A. decemarticulatus also destroys almost two-thirds of the floral buds of its host plant, resulting in very low fruit production (Malé et al. 2012). The castration behaviour of $A$. decemarticulatus is thus characterized by an intermediate level of virulence.

\section{Experimental Protocol}

A total of 54 flowering $H$. physophora inhabited by welldeveloped colonies of $A$. decemarticulatus were randomly assigned to one of three groups of 18 individuals. The plants in these groups were similar in terms of size, base diameter, and number of branches, leaves and inflorescences. Each group was subjected to one of the three following experimental treatments: (1) all of the inflorescences were cut off at an early stage in their development ('total castration'); (2) untreated plants underwent the natural, ant-induced partial castration ('intermediate castration'); and (3) ants were excluded from all of the inflorescences by applying rings of Tanglefoot ${ }^{\circledR}$ on either side of the peduncles on shoots previously protected by aluminium foil ('no castration'). At the beginning of the experiment, the youngest leaf on every branch was marked and then, each month, the number of new leaves and inflorescences was recorded. Over the course of the experiment, the plants were subjected to the same experimental treatment again when necessary (i.e. cutting off the inflorescences or excluding ants at an early stage of inflorescence development).

The experiment ended 17 months later, i.e. at the beginning of the fourth flowering period. Nine individuals (i.e. three in the 'total castration' group, four in the 'intermediate castration' group and two in the 'no castration' group) were not taken into account because of the death of their associated ant colony or of the plant itself over the course of the experiment. We recorded the number of remaining pre-treatment leaves. When possible, the two youngest pre-treatment leaves and two leaves that had reached maturity during the experiment were collected to compare morphological characteristics between them. For each leaf collected, we estimated its surface area using ImageJ v1.34 software and quantified the volumes of the two domatia. Domatia volume was estimated based on the volume of an ellipsoid for which the three elliptic radii were equal to the length, width and height of the domatium. We also counted the number of EFNs and measured the surface areas of four of them on the lamina and four others in the domatia.

We then assessed the effect of the experimental treatment on myrmecophytic characteristics by comparing (1) the domatia volumes, (2) the number of EFNs per leaf, and (3) the surface areas of the domatia and lamina EFNs based on the experimental treatment and with pre-treatment leaves. The plants' investment in vegetative parts was assessed by comparing the number of newly-produced leaves and the abscission rate of old leaves between the three groups. We also compared the surface areas of the leaves based on the three experimental treatments and with the pre-treatment leaves. The effect of the experimental treatments on plant investment in reproduction was quantified by comparing the final number of inflorescences between the three experimental groups.

We also sampled the youngest five leaves on one branch for 20 different plants and the penultimate leaf on up to eight branches for 20 other $H$. physophora individuals inhabited by $A$. decemarticulatus. The domatia volume and the number and surface area of the domatia EFNs were determined as described above. We counted the number of worker larvae in each domatium and then verified that $A$. decemarticulatus larvae were preferentially clustered in the penultimate pair of domatia. As a consequence, only the penultimate pair of domatia was used in the subsequent analyses. Since numerous domatia were devoid of larvae, we chose to test separately whether the presence/absence of larvae in the domatia was influenced by domatia volume, and, when larvae were present, whether their number was influenced by domatia volume.

\section{Statistical Analyses}

All of the statistical analyses were conducted using $\mathrm{R}$ (R Development Core Team 2009). The data were analyzed using generalized linear mixed-effect models (GLMM), most of them conducted with the lme function combined with the Anova function in the nlme and car packages, respectively (Pinheiro et al. 2009; Fox and Weisberg 
2011). Population or plant ID was modeled as a random block effect in all of the analyses. When appropriate, plant or leaf ID was nested in population/plant ID. We assessed model fit through the visual evaluation of residual plots and by using the Shapiro-Wilk normality test when appropriate. We tested for the autocorrelation and heteroskedasticity of the residuals by conducting the Durbin-Watson and Breusch-Pagan tests using, respectively, the dwtest and the bptest functions in the lmtest package (Zeileis and Hothorn 2002). When necessary, data were Box-Coxtransformed using the boxcox function in the MASS package (Venables and Ripley 2002). Because of their binomial nature, the abscission rate of old leaves and the probability of larval presence in the domatia were analyzed using the lmer function in the lme 4 package (Bates and Maechler 2009) combined with the Anova function.

\section{Results}

\section{Castrated Plants Produce More Leaves}

Non-castrated plants produced fewer leaves than totally or partially castrated ones (Fig. 1; see also electronic supplementary material), but bore as many remaining pre-treatment leaves (GLMM: $d f=2 ; \chi^{2}=0.067 ; p=0.9672$ ). There was, however, no significant difference in leaf production between totally and partially castrated plants (Fig. 1; see also electronic supplementary material). During the flowering

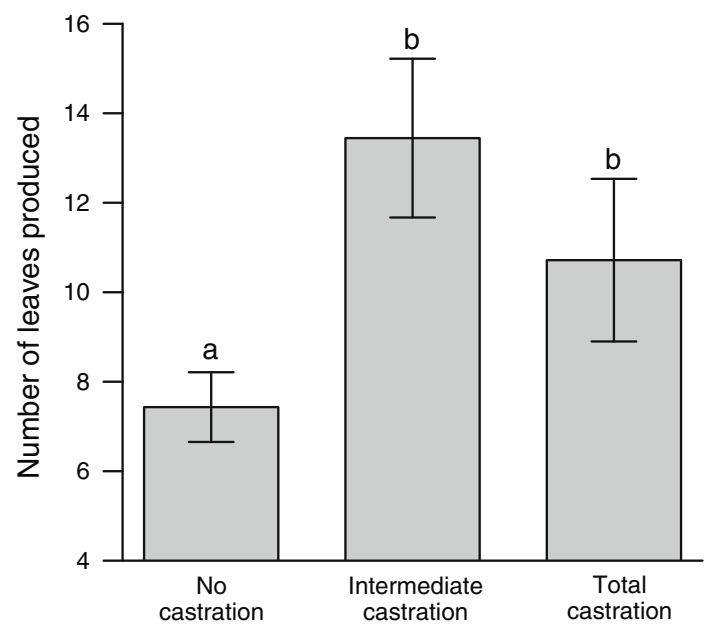

Fig. 1 Barplot of the mean ( \pm SE) number of leaves produced during the experiment as a function of the treatment ('No castration', plants with inflorescences from which ants were excluded; 'Intermediate castration', untreated plants experiencing natural, ant-induced partial castration; 'Total castration', plants with all of their inflorescences experimentally removed at an early stage). Population ID was taken into account as a random effect. Letters indicate significant differences in the number of leaves (GLMM, $p$ values $<0.05$ )
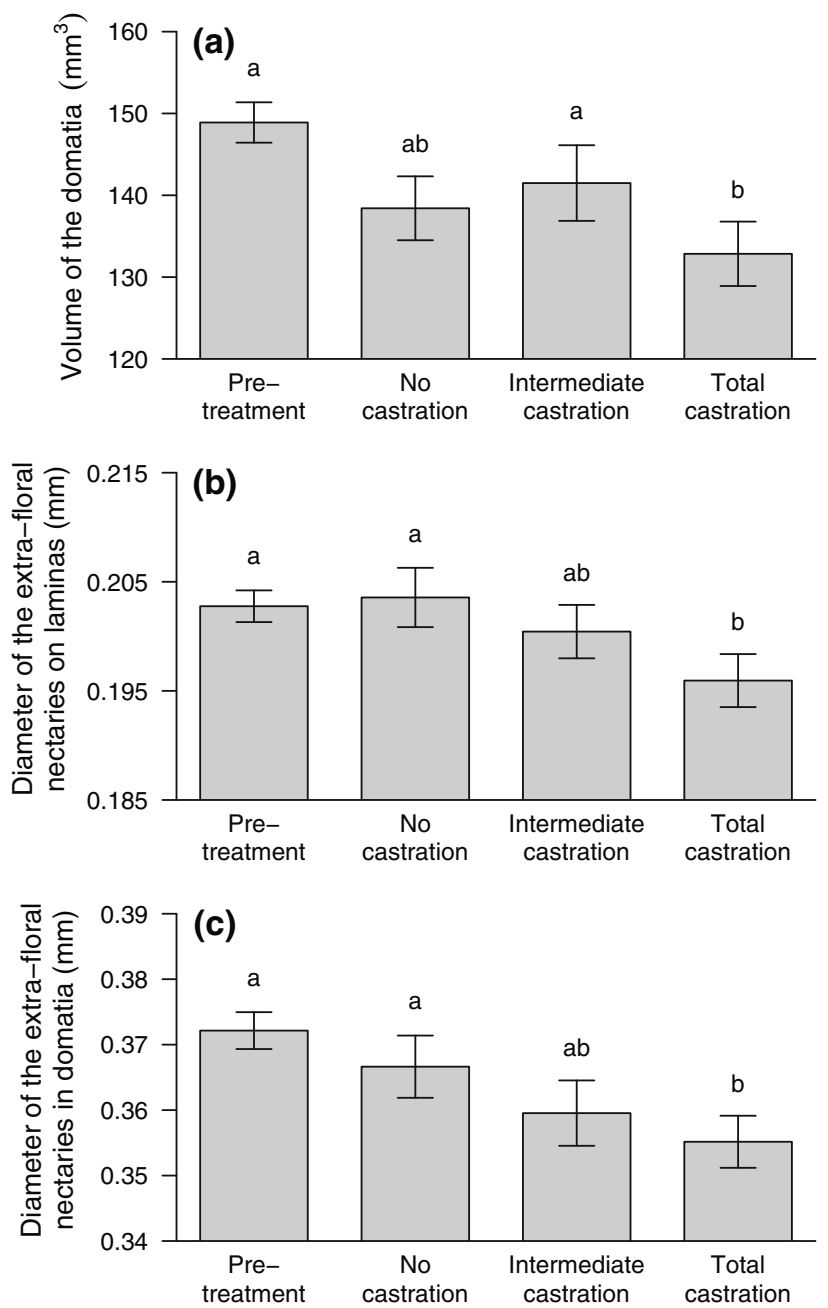

Fig. 2 Barplot of the mean $( \pm \mathrm{SE})$ for three morphological traits [a volume of domatia; $\mathbf{b}$ diameter of the extra-floral nectaries located on the laminas; $\mathbf{c}$ diameter of the extra-floral nectaries located inside the domatia] as a function of the treatment ('Pre-treatment', leaves produced before the beginning of the experiment; 'No castration', leaves produced during the experiment by plants with inflorescences from which the ants were excluded; 'Intermediate castration', leaves produced during the experiment by untreated plants (i.e. ant-induced, partial castration); 'Total castration', leaves produced during the experiment by plants with all of their inflorescences experimentally removed at an early stage). Plant ID was taken into account as a random effect. Letters indicate significant differences (GLMM, $p$ values $<0.05$ )

period that immediately followed the end of the experiment, the three groups produced the same number of inflorescences (GLMM: $d f=2 ; \chi^{2}=2.923, p=0.2319$ ). This result shows that the investment by plants in reproduction was not affected by the outcome of the previous flowering periods.

\section{Castrated Plants Produce Smaller Domatia}

The surface area of new leaves did not differ significantly according to the treatment or in comparison with pre-treatment 
leaves (GLMM: $d f=3 ; \chi^{2}=3.222, p=0.3587$ ), but new leaves on totally castrated plants bore significantly smaller domatia than did both pre-treatment leaves and leaves on plants which experienced partial castration by ants (GLMM: $d f=3$; $\chi^{2}=15.758, p=0.0013$; Fig. 2a; see also electronic supplementary material). Although the experimental treatment did not affect the total number of EFNs per leaf (GLMM: $d f=3$; $\left.\chi^{2}=1.346, p=0.7184\right)$, totally castrated plants produced leaves with significantly smaller lamina and domatia EFNs than both pre-treatment leaves and new leaves on non-castrated plants (GLMM, lamina EFN: $d f=3 ; \quad \chi^{2}=9.947$, $p=0.0190$; domatia EFN: $d f=3 ; \chi^{2}=7.903, p=0.0049$; Fig. 2b, c; see also electronic supplementary material).

\section{Smaller Domatia Shelter Less Ant Larvae}

In non-manipulated plants, worker larvae were preferentially clustered in the domatia of the penultimate leaf (GLMM: $d f=4 ; \chi^{2}=108.75, p<0.0001 ;$ Fig. 3 ; see also electronic supplementary material). The probability of larval presence in the penultimate pair of domatia increased with domatia volume but was influenced neither by the number of domatia EFNs, nor by the mean domatia EFN surface area (Table 1a). Similarly, when present, the quantity of larvae in the penultimate pair of domatia was also positively influenced by domatia volume, but not by the number of domatia EFNs or by the mean domatia EFN surface area (Table 1b). These results mean that the smaller the domatium, the less chances there are that it shelters any larvae, and if it nevertheless does, the less larvae it shelters.

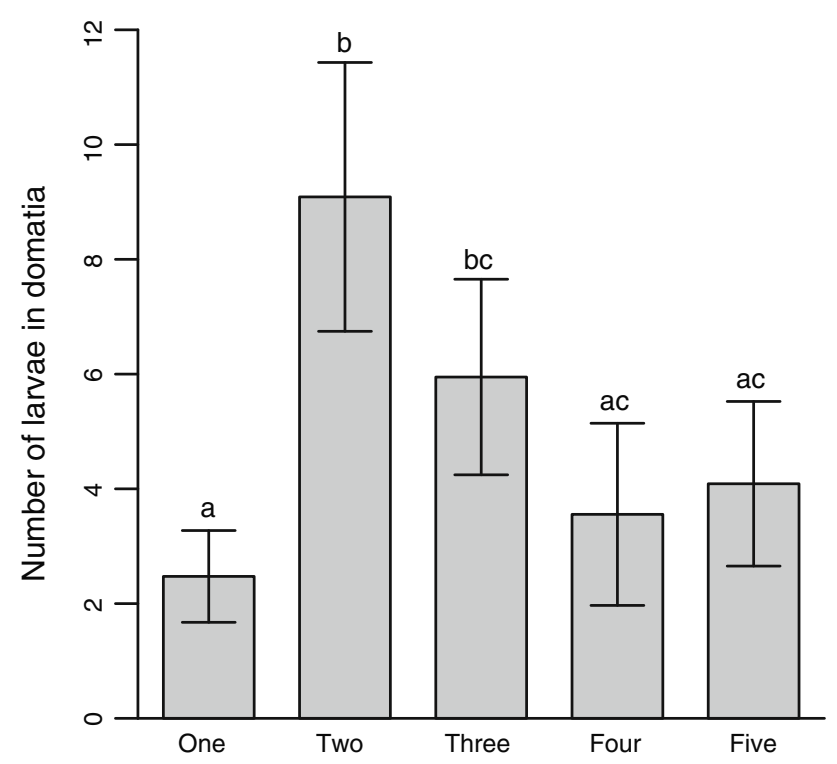

Fig. 3 Barplot of the mean ( \pm SE) number of larvae sheltered in the domatia as a function of the leaf location ('Leaf one', the youngest leaf on the branch; the other leaves are numbered subsequently). Letters indicate significant differences (GLMM, $p$ values $<0.05$ )

\section{Discussion}

Allomerus ants are known to destroy the inflorescences of their host plant (Frederickson 2009; Malé et al. 2012; Edwards and Yu 2008). Our results demonstrate that this castration behaviour induces an increase in the H. physophora growth rate: castrated plants produce more leaves than those bearing inflorescences from which ants have been excluded. This confirms the idea that A. decemarticulatus colonies obtain more living space than putative non-castrating ants thanks to their castrating behaviour. By castrating their host plant, A. decemarticulatus colonies thus exploit the trade-off between vegetative growth and reproduction in $H$. physophora. Consequently, the destruction of the plant's sexual organs can be assimilated to parasitic castration inducing gigantism (Hall et al. 2007) which has already been observed in another ant-plant interaction (Frederickson 2009).

We show that the total castration of $H$. physophora induces a decrease in its investment in myrmecophytic traits. This reduction affects both housing and food resources with a decrease in the domatia volume and a reduction in the surface areas of the EFNs, but does not affect non-myrmecophytic traits such as surface area of leaves. The loss of space resulting from the decrease in the volume of the domatia is likely to directly affect the development and fitness of too virulent colonies, as nesting space is a major limiting factor to the growth and reproduction of the A. decemarticulatus colonies (Orivel et al. 2011). Our results demonstrate that a reduction in the investment in myrmecophytic traits affects the newly-produced domatia that are, under natural conditions, the ones that host most of the ant brood. Moreover, the number of larvae that are hosted in a domatium depends on the volume of that domatium. As a consequence, the development of a putative fully-castrating ant colony is very likely to be slower than that of a partially-castrating ant colony. This slowing down in colony growth should directly translate into a loss of fitness because the production of alates in A. decemarticulatus has been shown to be positively correlated to the number of workers (Orivel et al. 2011).

One still might wonder if the decrease in domatia volume can be compensated by an increase in the number of domatia. Because the probability of sheltering larvae, and not only the number of larvae, is also negatively correlated to domatia volume, small domatia can be completely lost for the ant colony. As a consequence, the cost of total castration could be greater in terms of a loss in fitness for the ant colony than the net benefit of more leaves, i.e. nesting units, produced. Moreover, the cost of total castration also affects the size of the EFNs located inside the domatia. Since the quantity of nectar produced is proportional to the volume of the nectarial parenchyma 
Table 1 Effect of domatia volume, number of domatia EFNs and mean diameter of domatia EFNs on (a) presence/absence of larvae in domatia, and (b) number of larvae when present in domatia

\begin{tabular}{|c|c|c|c|c|c|}
\hline & Estimate & SE & DF & $\chi^{2}$ & $p$ value \\
\hline \multicolumn{6}{|l|}{ (a) Presence/absence of larvae in domatia } \\
\hline Domatia volume & 0.014 & 0.007 & 1 & 4.0052 & $0.0454^{*}$ \\
\hline Number of domatia EFNs & -0.101 & 0.161 & 1 & 0.3880 & 0.5334 \\
\hline Mean surface area of domatia EFNs & 1.556 & 2.824 & 1 & 0.3037 & 0.5816 \\
\hline \multicolumn{6}{|c|}{ (b) Number of larvae when present in domatia } \\
\hline Domatia volume & 0.016 & 0.005 & 1 & 10.003 & $0.0016 * *$ \\
\hline Number of domatia EFNs & -0.026 & 0.132 & 1 & 0.038 & 0.8460 \\
\hline Mean surface area of domatia EFNs & 0.662 & 1.907 & 1 & 0.121 & 0.7285 \\
\hline
\end{tabular}

$D F$ number of degrees of freedom, $S E$ standard error

* Statistical significance at the $5 \%$ level, ** Statistical significance at the $1 \%$ level

(Pacini et al. 2003), the smaller the EFNs, the less nectar they are believed to produce. Ants inhabiting totally castrated plants should thus experience a potentially harmful decrease in their carbohydrate intake which might potentially affect the performance of the colony (Dussutour and Simpson 2012). By analogy with plant-rhizobia interactions, both a reduction in living space and in the amount of food provided can be considered retaliation by the plant (West et al. 2002). Such retaliation mechanisms against castrating parasites are shown here for the first time in the framework of ant-plant interactions.

The destruction of a fraction of the sexual organs seems to be the best compromise because it maximizes the costto-benefit ratio for both partners. Retaliation was only detected when the virulence of the castration was at its maximum. As a consequence, over the long term, it is unlikely that ants that totally castrate their host plant gain a fitness advantage compared to ants with an intermediate level of virulence. Nevertheless, intermediate castration virulence is not an optimum situation for $H$. physophora. Plants with a lower tolerance to castration should obtain a higher fitness benefit. But the global fitness of an individual has to be considered over its lifespan. Indeed, Palmer et al. (2010) demonstrated that the provisional association with sterilizing ants enhanced the lifetime fitness of Acacia drepanolobium. As the energy that a plant invests in reproduction is lost for vegetative investment, there is a trade-off between reproduction and survival, leading to a trade-off between current reproductive output and future reproduction (Obeso 2002). The ant-induced reduction in one reproductive event is thus likely to result in an increase in the life expectancy of the plant, and, consequently, in an increase in the plant's subsequent reproductive success.

Acknowledgments We are grateful to the Laboratoire Environnement de Petit Saut and the Nouragues scientific station for furnishing logistical help, to Dr. Jacqui Shykoff and Pr. Doyle McKey for insightful comments and to Andrea Yockey-Dejean for proofreading the manuscript. Financial support for this study was provided by a research program of the French Agence Nationale de la Recherche (research agreement $n^{\circ}$ ANR-06-JCJC-0109-01), by the ESF-EUROCORES/TECT/BIOCONTRACT program, by the Fondation pour la Recherche sur la Biodiversité (research agreement $\mathrm{n}^{\circ} \mathrm{AAP}-\mathrm{IN}-2009$ 050), by the Programme Convergence 2007-2013 Région Guyane from the European Community, and by the Programme Amazonie II of the French Centre National de la Recherche Scientifique. This work has benefited from "Investissement d'Avenir" grants managed by the Agence Nationale de la Recherche (CEBA, ref. ANR-10LABX-25-01 and TULIP, ref. ANR -10-LABX-0041).

\section{References}

Bates, D., \& Maechler, M. (2009). lme4: Linear mixed-effects models using S4 classes. (R package version 0.999375-32 ed.).

Best, A., White, A., \& Boots, M. (2009). Resistance is futile but tolerance can explain why parasites do not always castrate their hosts. Evolution, 64(2), 348-357. doi:10.1111/j.1558-5646.2009. 00819.x.

Bronstein, J. L. (2001). The exploitation of mutualisms. Ecology Letters, 4(3), 277-287.

Douglas, A. E. (2008). Conflict, cheats and the persistence of symbioses. New Phytologist, 177(4), 849-858. doi:10.1111/ j.1469-8137.2007.02326.x.

Douglas, A. E. (2010). The symbiotic habit. Princeton and Oxford: Princeton University Press.

Dussutour, A., \& Simpson, S. J. (2012). Ant workers die young and colonies collapse when fed a high-protein diet. In Proceedings of the Royal Society B-Biological Sciences: online. doi:10.1098/ rspb.2012.0051.

Edwards, D. P., Ansell, F. A., Woodcock, P., Fayle, T. M., Chey, V. K., \& Hamer, K. C. (2010). Can the failure to punish promote cheating in mutualism? Oikos, 119, 45-52. doi:10.1111/j.16000706.2009.17591.x.

Edwards, D. P., Hassall, M., Sutherland, W. J., \& Yu, D. W. (2006). Selection for protection in an ant-plant mutualism: host sanctions, host modularity, and the principal-agent game. Proceedings of the Royal Society B-Biological Sciences, 273, 595-602. doi:10.1098/ rspb.2005.3273. 
Edwards, D. P., \& Yu, D. W. (2008). Tolerating castration by hiding flowers in plain sight. Behavioral Ecology and Sociobiology, 63(1), 95-102. doi:10.1007/s00265-008-0639-8.

Fonseca, C. R. (1993). Nesting space limits colony size of the plantant Pseudomyrmex concolor. Oikos, 67, 473-482.

Fox, J., \& Weisberg, S. (2011). An $R$ companion to applied regression. Thousand Oaks, CA: Sage.

Frederickson, M. E. (2009). Conflict over reproduction in an ant-plant symbiosis: Why Allomerus octoarticulatus ants sterilize Cordia nodosa trees? American Naturalist, 173(5), 675-681. doi:10. $1086 / 597608$.

Gaume, L., Zacharias, M., \& Borges, R. M. (2005). Ant-plant conflicts and a novel case of castration parasitism in a myrmecophyte. Evolutionary Ecology Research, 7, 435-452.

Gilbert, F. S., Haines, N., \& Dickson, K. (1991). Empty flowers. Functional Ecology, 5, 29-39.

Grangier, J., Dejean, A., Malé, P.-J. G., \& Orivel, J. (2008). Indirect defense in a highly specific ant-plant mutualism. Naturwissenschaften, 95(10), 909-916. doi:10.1007/s00114-008-0398-4.

Grangier, J., Dejean, A., Malé, P.-J. G., Solano, P.-J., \& Orivel, J. (2009). Mechanisms driving the specificity of a myrmecophyteant association. Biological Journal of the Linnean Society, 97, 90-97. doi:10.1111/j.1095-8312.2008.01188.x.

Hall, S. R., Becker, C., \& Cáceres, C. E. (2007). Parasitic castration: A perspective from a model of dynamic energy budgets. Integrative and Comparative Biology, 47(2), 295-309. doi:10.1093/ $\mathrm{icb} / \mathrm{icm} 057$.

Heil, M., \& McKey, D. (2003). Protective ant-plant interactions as model systems in ecological and evolutionary research. Annual Review of Ecology Evolution and Systematics, 34, 425-453.

Herre, E. A., Knowlton, N., Mueller, U. G., \& Rehner, S. A. (1999). The evolution of mutualisms: Exploring the paths between conflict and cooperation. Trends in Ecology \& Evolution, 14(2), 49-53. doi:10.1016/S0169-5347(98)01529-8.

Inouye, D. W. (1983). The ecology of nectar robbing. In B. Bentley \& T. Elias (Eds.), The biology of nectaries. New York, USA: Columbia University Press.

Izzo, T. J., \& Vasconcelos, H. L. (2002). Cheating the cheater: Domatia loss minimizes the effects of ant castration in an Amazonian ant-plant. Oecologia, 133, 200-205. doi:10.1007/ s00442-002-1027-0.

Jaenike, J. (1996). Suboptimal virulence of an insect-parasitic nematode. Evolution, 50(6), 2241-2247.

Leroy, C., Jauneau, A., Quilichini, A., Dejean, A., \& Orivel, J. (2008). Comparison between the anatomical and morphological structure of leaf blades and foliar domatia in the ant-plant Hirtella physophora (Chrysobalanaceae). Annals of Botany, 101, 501-507. doi:10.1093/aob/mcm323.

Leroy, C., Jauneau, A., Quilichini, A., Dejean, A., \& Orivel, J. (2010). Comparative structure and ontogeny of the foliar domatia in three neotropical myrmecophytes. American Journal of Botany, 97, 557-565. doi:10.3732/ajb.0900207.

Malé, P.-J. G. (2011). Stabilité évolutive des mutualismes et mécanismes de contrôle : le cas d'une relation plante-fourmis. $\mathrm{PhD}$ thesis, Université de Toulouse, Toulouse, France.
Malé, P.-J. G., Leroy, C., Dejean, A., Quilichini, A., \& Orivel, J. (2012). An ant symbiont directly and indirectly limits its host plant's reproductive success. Evolutionary Ecology, 26(1), 55-63. doi:10.1007/s10682-011-9485-7.

Obeso, J. R. (2002). The cost of reproduction in plants. New Phytologist, 155, 321-348. doi:10.1046/j.1469-8137.2002.00477.x.

O'Keefe, K. J., \& Antonovics, J. (2002). Playing by different rules: The evolution of virulence in sterilizing pathogens. American Naturalist, 159(6), 597-605. doi:10.1086/339990.

Orivel, J., Lambs, L., Malé, P.-J. G., Leroy, C., Grangier, J., Otto, T., et al. (2011). Dynamics of the association between a long-lived understory myrmecophyte and its specific associated ants. Oecologia, 165, 369-376. doi:10.1007/s00442-010-1739-5.

Pacini, E., Nepi, M., \& Vesprini, J. L. (2003). Nectar biodiversity: A short review. Plant Systematics and Evolution, 238, 7-21. doi:10.1007/s00606-002-0277-yNectar.

Palmer, T. M., Doak, D. F., Stanton, M. L., Bronstein, J. L., Kiers, E. T., Young, T. P., et al. (2010). Synergy of multiple partners, including freeloaders, increases host fitness in a multispecies mutualism. Proceedings of the National Academy of Sciences, 107(40), 17234-17239.

Pinheiro, J., Bates, D., DebRoy, S., Sarkar, D., \& The R Core Team. (2009). nlme: Linear and Nonlinear Mixed Effects Models. (R package version 3.1-96 ed.).

R Development Core Team (2009). R: A Language and Environment for Statistical Computing. In R. F. f. S. Computing (Ed.). Vienna, Austria.

Solano, P.-J., Durou, S., Corbara, B., Quilichini, A., Cerdan, P., Belin-Dupoux, M., et al. (2003). Myrmecophytes of the understory of French Guianian rainforests: Their distribution and their associated ants. Sociobiology, 41(3), 605-614.

Szilágyi, A., Scheuring, I., Edwards, D. P., Orivel, J., \& Yu, D. W. (2009). The evolution of intermediate castration virulence and ant coexistence in a spatially structured environment. Ecology Letters, 12(12), 1306-1316.

Venables, W. N., \& Ripley, B. D. (2002). Modern applied statistics with $S$ (4th ed.). New York: Springer.

Watson, M. A. (1984). Developmental constraints: effect on population growth and patterns of resource allocation in a clonal plant. American Naturalist, 123(3), 411-426. doi:10.1086/ 284212.

West, S. A., Kiers, E. T., Simms, E. L., \& Denison, R. F. (2002). Sanctions and mutualism stability: Why do rhizobia fix nitrogen? Proceedings of the Royal Society B-Biological Sciences, 269, 685-694. doi:10.1098/rspb.2001.1878.

Wilkinson, D. M., \& Sherratt, T. N. (2001). Horizontally acquired mutualisms, an unsolved problem in ecology? Oikos, 92(2), 377-384. doi:10.1034/j.1600-0706.2001.920222.x.

Yu, D. W., \& Pierce, N. E. (1998). A castration parasite of an antplant mutualism. Proceedings of the Royal Society B-Biological Sciences, 265, 375-382. doi:10.1098/rspb.1998.0305.

Zeileis, A., \& Hothorn, T. (2002). Diagnostic checking in regression relationships. $R$ News, 2(3), 7-10. 